\title{
CaMKIV limits metabolic damage through induction of hepatic autophagy by CREB in obese mice
}

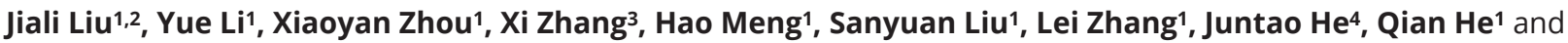
Yan Geng1

1Department of Clinical Laboratory, The Second Affiliated Hospital of Xi'an Jiaotong University, Xi'an, Shaanxi, China 2Leonard Davis School of Gerontology, University of Southern California, Los Angeles, California, USA

3Department of Neurosurgery, The Second Affiliated Hospital of Xi'an Jiaotong University, Xi'an, Shaanxi, China 4Department of Health Office, The Second Affiliated Hospital of Xi'an Jiaotong University, Xi'an, Shaanxi, China

Correspondence should be addressed to Q He or Y Geng: qianh0511@163.com or gengyanxjtu@gmail.com

\begin{abstract}
High-fat diet (HFD) not only induces insulin resistance in liver, but also causes autophagic imbalance and metabolic disorders, increases chronic inflammatory response and induces mitochondrial dysfunction. Calcium/calmodulin-dependent protein kinase IV (CaMKIV) has recently emerged as an important regulator of glucose metabolism and skeletal muscle insulin action. Its activation has been involved in the improvement of hepatic and adipose insulin action. But the underlying mechanism is not fully understood. In the present study, we aimed to address the direct effects of CaMKIV in vivo and to evaluate the potential interaction of impaired insulin sensitivity and autophagic disorders in hepatic insulin resistance. Our results indicated obese mice receiving CaMKIV showed decreased blood glucose and serum insulin and improved insulin sensitivity as well as increased glucose tolerance compared with vehicle injection. Meanwhile, defective hepatic autophagy activity, impaired insulin signaling, increased inflammatory response and mitochondrial dysfunction in liver tissues which are induced by high-fat diet were also effectively alleviated by injection of CaMKIV. Consistent with these results, the addition of CaMKIV to the culture medium of BNL cl.2 hepatocytes markedly restored palmitate-induced hepatic insulin resistance and autophagic imbalance. These effects were nullified by blockade of cyclic AMP response elementbinding protein (CREB), indicating the causative role of CREB in action of CaMKIV. Our findings suggested that CaMKIV restores hepatic autophagic imbalance and improves impaired insulin sensitivity via phosphorylated CREB signaling pathway, which may offer novel opportunities for treatment of obesity and diabetes.
\end{abstract}
Key Words
- CaMKIV
high-fat diet
- CREB
- autophagy
- insulin resistance

Journal of Endocrinology (2020) 244, 353-367

\section{Introduction}

In recent years, there has been an increasing appreciation for the significance of insulin resistance, which is a common feature of obesity and predisposes affected individuals to a variety of pathological conditions, including hypertension, dyslipidemia, cardiovascular disease, and type 2 diabetes (Samuel \& Shulman 2012, Odegaard \& Chawla 2013, Tangvarasittichai 2015, Craft \& Rhoads 2016). Liver is now recognized as not only an 
energy control tissue but also a target organ of insulin that contributes to the systemic insulin resistance and metabolic inflammation (Calomeni et al. 2013, Koliaki \& Roden 2013, Li et al. 2014b, Bojsen-Møller et al. 2018). Although considerable progress has been made in understanding the molecular mechanisms underlying these individual disorders, satisfactory treatment modalities remain

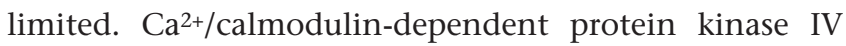
(CaMKIV), a multifunctional serine/threonine protein kinase encoded by the CaMKIV gene in human, plays a critical role in the process of transcriptional regulation of lymphocytes, neurons and male germ cells. Of note, CaMKIV has recently emerged as an important regulator in insulin-stimulated glucose metabolism and involved in whole-body improvements of insulin sensitivity (Wu et al. 2000, Hook \& Means 2001, Lee et al. 2014).

CaMKIV, also known as CaMK4, has been shown to regulate various cellular events through phosphorylated transcription factors. It plays an essential role in immune response, inflammation and memory consolidation (Hanissian et al. 1993, Kang et al. 2001, Fukushima et al. 2008, Racioppi \& Means 2008). However, recent studies supported a novel function of CaMKIV in regulating the systemic insulin action. For instance, the signal CaMKK/ CaMKIV cascade plays an important role in glucoseupregulated transcriptional activation of the insulin gene in both pancreatic beta cells and the insulin-secreted cell line (Yu et al. 2004). Activated CaMKIV mediated the stimulatory effect of glucose-dependent insulin secretion through exendin- 4 which may improve the function of pancreatic beta cells by the activation of glucokinase (Murao et al. 2009). In addition, another research has demonstrated that CaMKIV plays a significant role in CREB-dependent mechanism by which glucose regulates Irs 2 but not Irs1 gene expression in beta cells, it is interesting to note that in these cells, overproduction of a dominant negative form of CREB completely suppressed glucose and CaMKIV stimulation of Irs2 expression (Persaud et al. 2011). Lee and colleagues assessed insulin sensitivity in both wild-type (WT) mice and the novel transgenic mice (CaMKIV). The results suggested that the expression of an active form of CaMKIV in muscle improved insulin-stimulated muscle glucose uptake, with increases in GLUT4 content and improvements in insulin signaling. Also, CaMKIV activation could improve hepatic and adipose insulin action via increase in myokines released from the skeletal muscle (Lee et al. 2014).

Although the role of CaMKIV in insulin signaling has only recently been identified, the functional basis for the effect in the autophagy-mediated insulin signaling

(C) 2020 Society for Endocrinology Published by Bioscientifica Ltd. Printed in Great Britain pathway remains elusive. However, the relevance of CaMKIV to autophagic response has been implicated that CaMKIV activates autophagy in vitro and prevents oxidative stress-induced cell death, and augmentation of autophagy in CaMKIV KO mice restored organ damage to WT levels (Evankovich et al. 2012). Moreover, another study suggested that CaMKIV serves a permissive role of LPS-induced autophagy in $\mathrm{M} \phi$ and renal tubular cells by inhibiting GSK3 $\beta$ and FBXW7-mediated ubiquitination and proteasomal degradation of mTOR and titrates basal mTOR expression (Zhang et al. 2014). In addition, phosphorylation of CREB, a critical transcription factor for several forms of experience-dependent plasticity in a range of species, is commonly activated by CaMKIV. We therefore hypothesized that CaMKIV could affect liver functions, such as regulation of insulin signaling and autophagy activity. In this study, we aimed to address the direct effects of CaMKIV in vivo and to evaluate the potential interaction of impaired insulin sensitivity and autophagic disturbance during this process. Our results support the therapeutic potential of this new player in the regulation of hepatic insulin resistance and metabolic disorders.

\section{Materials and methods}

\section{Materials}

The following regents were purchased from Sigma (SigmaAldrich): Palmitate (FFA), insulin, chloroquine, 3-MA and 666-15. Mouse recombinant CaMKIV was obtained from Sino Biological (Sino Biological Inc. Wayne, PA, USA). The following antibodies were used: anti-Atg7 (1:1000, \#2631), anti-p62 (1:500, \#5114), and anti-LC3 (1:500, \#4108), anti-CREB (1:5000, \#9197), anti-p-CREB (1:1000, \#9198) (all from Cell Signaling Technology Inc.); anti-CaMKIV (1:1000, sc-55501), anti-p-IRS-1 (1:300, sc-17200), anti-pY20 (1:300, sc-508), anti-Akt (1:500, sc-5298), antip-Akt (1:400, sc-377556), anti-GAPDH (1:5000, sc-47724) and peroxidase goat anti-rabbit IgG (1:3000, sc-2768) and peroxidase goat anti-mouse IgG (1:3000, sc-2357) (Santa Cruz Biotechnology Inc.). For detection, a Western Lightning Plus-ECL Enhanced Chemiluminescence Substrate Kit (PerkinElmer Inc.) was used. Individual protein bands were quantified by ImageJ software. All other chemicals were obtained from standard resource and were of the highest grade available.

\section{Animals and treatment}

All studies were approved by the Xi'an Jiaotong University Laboratory Animal Administration Committee and 
performed according to the Xi'an Jiaotong University Guidelines for Animal Experimentation. For in vivo experiments, 4-week-old C57BL/6J male mice were obtained from Medical Experimental Animal Center of $\mathrm{Xi}^{\prime}$ an Jiaotong University. Mice were maintained in a temperature- $\left(22^{\circ} \mathrm{C}\right)$, humidity-, and light- $(12 \mathrm{~h}$ of light, $12 \mathrm{~h}$ of darkness, darkness from 19:30 h to 7:30 h) - controlled environment. Recombinant mouse CaMKIV was freshly diluted in saline solution $(0.9 \% \mathrm{NaCl})$ at a concentration of $1 \mu \mathrm{g} / \mu \mathrm{L}$. Mice were distributed in four groups (15 mice/group): (1) ND+vehicle (normal diet+saline solution intraperitoneally i.p.); (2) ND+CaMKIV (normal diet + recombinant mouse CaMKIV, i.p. $1 \mu \mathrm{g} / \mathrm{g}$ body weight/ day); (3) HFD+vehicle (diet containing 60\% of energy as fat, $5.24 \mathrm{kcal} / \mathrm{g}+$ saline solution intraperitoneally i.p.); (4) HFD + CaMKIV (diet containing $60 \%$ of energy as fat, $5.24 \mathrm{kcal} / \mathrm{g}+$ recombinant mouse CaMKIV, i.p. $1 \mu \mathrm{g} / \mathrm{g}$ body weight/day). At the end of the 12 -week study period, mice received vehicle or an intraperitoneal injection of insulin at a dosage of $2 \mathrm{IU} / \mathrm{kg}$ for the insulin signaling test; 15 min after the injection, all animals were killed and their liver tissues and blood samples were obtained and stored at $-80^{\circ} \mathrm{C}$ for subsequent analysis.

\section{Cell culture and treatment}

BNL cl.2 cells were purchased from American Tissue Culture Collection (ATCC) and maintained at $37^{\circ} \mathrm{C}$ in a humidified atmosphere of $5 \% \mathrm{CO}_{2}$ in DMEM (Gibco) with $10 \%$ fetal bovine serum (Gibco). To induce insulin resistance, cells were treated with $500 \mu \mathrm{M}$ of palmitate (FFA) for $16 \mathrm{~h}$. For the effect of CaMKIV, cells were treated with $100 \mathrm{ng} / \mathrm{mL}$ of CaMKIV for $20 \mathrm{~h}$. For blocking CREB signaling, cells were treated with $100 \mathrm{nM}$ of CREB inhibitor 666-15 for $24 \mathrm{~h}$. For insulin signaling, cells were stimulated with $10 \mathrm{nM}$ insulin for $10 \mathrm{~min}$. Before each experiment, the medium was replaced by fresh medium.

\section{Measurement of serum parameters and metabolic tests}

After collection, serum was stored at $-80^{\circ} \mathrm{C}$ before analysis. Serum triglycerides were measured by colorimetric enzymatic method using commercial kits (SGM Italia, Italy and Randox Laboratories Ltd., UK). Serum FFA was measured using an ELISA kit (Abcam) according to the manufacturer's instructions. Serum TNF- $\alpha$, IL-6, MCP-1 and FGF-21 were measured using the commercially available ELISA kit (R\&D Systems, Inc.). Glucose tolerance testing (GTT) was performed after the mice were fasted overnight. Insulin tolerance testing (ITT) was performed after mice were fasted for $6 \mathrm{~h}$. Metabolic tests were performed using a standard protocol as described previously (Zhou et al. 2013). Hepatic glycogen content was measured using an EnzyChrom ${ }^{\mathrm{TM}}$ Glycogen Assay Kit (BioAssay Systems, Hayward, CA, USA) according to the manufacturer's instructions.

\section{Gene silencing}

siRNA for target genes (CaMKIV: sc-29903, CREB: sc-29903, Atg7: sc-41448, Santa Cruz Biotechnology, Inc.) or scrambled siRNA (Control, sc-37007, Santa Cruz Biotechnology, Inc.) were transfected using Lipofectamine $^{\mathrm{TM}} 2000$ Transfection Reagent (Invitrogen). The transfected cells were cultured in DMEM containing $10 \%$ FBS for $48 \mathrm{~h}$ after transfection.

\section{mRNA isolation and analysis by real-time PCR}

Total RNA was prepared from isolated liver tissues or BNL cl.2 cells by TRIzol extraction (Qiagen) according to the manufacturer's recommendations. Total RNA $(1 \mu \mathrm{g})$ was converted into cDNA using a cDNA synthesis kit (Invitrogen). $\beta$-Actin was used as an internal control and tests were performed in triplicate for each sample. The relative quantity was calculated using the $2^{-\Delta \Delta C t}$ method. Quantitative real-time PCR analysis was performed as described previously (Liu et al. 2015). The specific primer sequences were shown in Table 1.

\section{Liver tissues histomorphometry}

As described previously (Zhou et al. 2013), liver tissues were fixed in solution and washed. Samples were next sectioned at $10 \mu \mathrm{m}$ using a cryostat. The sections were stained with Oil Red O kit (Abcam) according to the manufacturer's instructions. The Oil Red O-positive area over the total area was quantified using ImageJ software.

\section{Electron microscopy analysis}

The isolated muscle tissues, adipose tissues and liver tissues were first fixed in a solution comprising $4 \%$ paraformaldehyde, 2\% glutaraldehyde, and $0.1 \mathrm{M}$ sodium cacodylate ( $\mathrm{pH}$ 7.3), post fixed in $1 \%$ osmium tetraoxide and then embedded in epoxy resin (Epon). Ultrathin sections $(80 \mathrm{~nm})$ were stained with aqueous uranyl acetate and lead citrate and then examined with 
Table 1 The sequences of primers for real-time PCR.

\begin{tabular}{l}
\hline Target gene \\
\hline TNF- $\alpha$ \\
IL-6 \\
MCP-1 \\
Fgf-21 \\
p62 \\
Srebf1c \\
Pparg \\
Fasn \\
Acaca \\
Scd1 \\
Dgat2 \\
G6pc \\
Pck1 \\
$\beta-A c t i n$ \\
GAPDH
\end{tabular}

\begin{tabular}{l}
\hline Sense \\
\hline 5'-TTCTGTCTACTGAACTTCGGGGTGATCGGTCC-3' \\
5'-AACGATGATGCACTTGCAGA-3' \\
5'-CCCACTCACCTGCTGCTACT-3' \\
5'-AGATCAGGGAGGATGGAACA-3' \\
5'-TGTGGAACATGGAGGGAAGAG-3' \\
5'-TGGAGACATCGCAAACAAG-3' \\
5'-GACATCAAGCCTTTACCACA-3' \\
5'-GCAGCAAGTGTCCACCAACAA-3' \\
5'-GAGTGACTGCCGAAACATCTCTG-3' \\
5'-CTGCCTCTTCGGGATTTTCTACT-3' \\
5'-GAGGGGTCTGGGCGATGGGGCACT-3' \\
5'-CGACTCGCTATCTCCAAGTGA-3' \\
5'-GTGCTGGAGTGGATGTTCGG-3' \\
5'-TGTCCACCTTCCAGCAGATGT-3' \\
5'-ACCCAGAAGACTGTGGATGG-3'
\end{tabular}

\begin{tabular}{l}
\hline Anti-sense \\
\hline 5'-GTATGAGATAGCAAATC GGCTGACGGTGTGGG-3' \\
5'-GAGCATTGGAAATTGGGGTA-3' \\
5'-TCTGGACCCATTCCTTCTTG-3' \\
5'-ATCAAAGTGAGGCGATCCATA-3' \\
5'-TGTGCCTGTGCTGGAACTTTC-3' \\
5'-GGTAGACAACAGCCGCATC-3' \\
5'-GCTCTTGTGAATGGAATGTCTTC-3' \\
5'-CTCATCGGAGCGCAGGATAGA-3' \\
5'-GCCTCTTCCTGACAAACGAGT-3' \\
5'-GCCCATTCGTACACGTGATTC-3' \\
5'-CGACGGTGGTGATGGGCTTGGAGT-3' \\
5'-GTTGAACCAGTCTCCGACCA-3' \\
5'-CTGGCTGATTCTCTGTTTCAGG-3' \\
5'-AGCTCAGTAACAGTCCGCCTAGA-3' \\
5'-CACATTGGGGGTAGGAACAC-3'
\end{tabular}

a transmission electron microscope (2000FX. JEOL, Peabody, MA, USA). Sixteen electron micrographs of each mouse were digitized, and the area and number of clearly distinguishable mitochondria were analyzed using imageanalysis software (Osteomeasure; OsteoMetrics, Decatur, GA, USA).

\section{Autophagy flux analysis}

Chloroquine experiment was described as previously (Zois et al. 2011, Cho et al. 2014). Chloroquine dissolved in PBS was injected s.c. at a dose of $50 \mathrm{mg} / \mathrm{kg}$ body weight, and mice were killed $24 \mathrm{~h}$ following the injection. Vehicletreated mice were injected s.c. with an equal volume of sterile PBS solution. The injection dose of chloroquine was determined based on previous reports and our preliminary study, which had no detectable effect on liver function. After the dissection, the liver tissues were immediately homogenized in lysis buffer for Western blotting analysis.

\section{Western blot and immunoprecipitation}

Western blotting and immunoprecipitation were performed using a standard protocol as described previously (Li et al. 2014a). Positive Western blot loading control was used to identify the stability of the system. A standard sample was run in each blot to compare density values between blots by expressing each band density value as fold of this standard sample. Immunocomplexes were resolved by means of SDS-PAGE and immunoblotted with the indicated antibodies. The relative quantity of proteins was analyzed using the ImageJ software.

\section{Statistics}

Data were analyzed by the Prism software, version 5.0 (GraphPad Software Inc.). Characteristics of subjects between two groups was performed using an unpaired, two-tailed Student $t$ test for normally distributed variables. Multiple comparisons of quantitative variables among groups were made using one-way ANOVA testing. Data were presented as mean \pm s.D. $n$ represents the number of animals used. A $P$ value of $<0.05$ or $P$ value of $<0.01$ was considered as significantly different.

\section{Results}

CaMKIV administration protects from the glucose intolerance and insulin resistance induced by highfat feeding mice

To address the effects of CaMKIV on glucose metabolism and insulin sensitivity in vivo, mice were administered recombinant mouse CaMKIV i.p daily at the dosage of $1 \mu \mathrm{g} / \mathrm{g}$ body weight under a normal diet condition or HFD condition started from 4 th to 12 th week. The mean body weight of all mice groups, measured during the whole experimental period, shown in Fig. 1A. HFD feeding clearly led to a significant increase in body weight. These data were confirmed by the area under the curve (AUC) of body weight, calculated during the period (4th to 12 th week) (Fig. 1B). The groups on HFD showed a similar body weight much higher than ND-fed mice. Compared with mice cotreated with ND and vehicle injection, after 12-week study period, obese mice with vehicle treatment exhibited obesity and decreased glucose tolerance and insulin sensitivity as measured by GTT and 

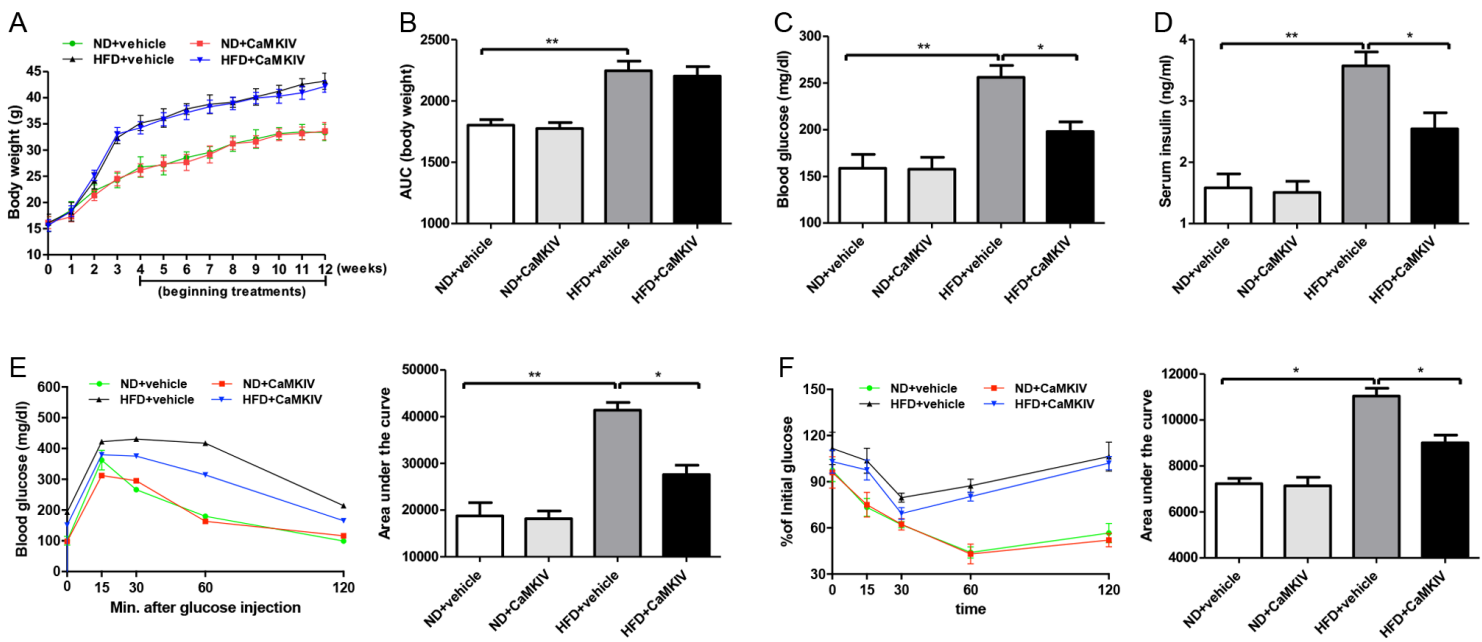

\section{Figure 1}

Effect of recombinant mouse CaMKIV on glucose metabolism and insulin sensitivity in HFD-fed mice. All analyses compared age- and sex-matched mice fed a normal diet (ND) or high-fat diet (HFD) for 12 weeks and injected with CaMKIV (1 $\mu \mathrm{g} / \mathrm{g} /$ day) or vehicle in the last 8 weeks. (A) Body weight. (B) AUC of body weight during time (4th-12th week). (C) Blood glucose. (D) Serum insulin. (E) GTT. (F) ITT. Data are expressed as means \pm S.D. in each bar graph from 12 to 15 mice per group. $* P<0.05$ or $* \star P<0.01$. A full colour version of this figure is available at https://doi.org/10.1530/JOE-19-0251.

ITT, respectively. But administration of CaMKIV could improve the HFD-induced glucose intolerance and insulin resistance (Fig. 1E and F). Meanwhile, obese mice with vehicle injection also showed elevated blood glucose and higher serum insulin level. However, injection of CaMKIV could reverse this phenomenon in obese mice (Fig. 1C and D). Taken together, these results indicated obese mice with CaMKIV treatment had an improved capability on glucose metabolism in vivo.

\section{Effect of CaMKIV on hepatic glucose and lipid metabolism}

As the major organ regulates glucose and lipid metabolism in the body, liver also plays a central role in the synthesis and degradation of fatty acids. To address the role of CaMKIV on glucose and lipid metabolism, mice were fasted $16 \mathrm{~h}$ before killing. We first analyzed mice liver weight and steatosis. These results showed there was no difference in liver weight and lipid accumulation between obese mice with CaMKIV or vehicle injection (Fig. 2A and B). However, serum free fatty acid was found markedly decreased in obese mice with CaMKIV treatment compared with vehicle injection (Fig. 2C). Similar results were also observed in serum triglyceride (Fig. 2D). In addition, the vehicle injection in obese mice showed increased levels of glycogen in liver tissues, whereas the levels were significantly decreased after CaMKIV injection (Fig. 2E). Consistent with these data, the expression of hepatic glucoregulatory genes G6pc and Pck1 in mRNA (Fig. 2F) and their protein levels (Supplementary Fig. 1A, see section on supplementary materials given at the end of this article) were markedly increased in obese mice with vehicle treatment. However, CaMKIV treatment in obese mice showed a reduced mRNA and protein expression of G6pc and Pck1 compared with obese mice treated with vehicle. To further insight into the liver fatty acid and triacylglycerol synthesis, we therefore decided to evaluate the expression of some lipogenic genes in mRNA and protein levels. The results demonstrated the expression of these genes were markedly upregulated in obese mice with vehicle treatment (Fig. 2G and Supplementary Fig. 1B). However, CaMKIV treated with obese mice showed a significant decrease in liver tissues (Fig. 2G and Supplementary Fig. 1B), indicating the improved hepatic glucose and lipid metabolism may contribute to the CaMKIV-induced effects.

\section{Effect of CaMKIV on mitochondrial functions and efficiency}

Numerous studies in human and animal models have shown that obesity or insulin resistance is frequently associated with reduced mitochondrial mass and impaired mitochondrial function in insulin sensitivity tissues (Petersen et al. 2004, Koliaki et al. 2015, Montgomery \& Turner 2015). To clarify the mediator of effect of CaMKIV on mitochondrial function, we performed molecular and histomorphometric analysis in mice. Our results demonstrated the critical genes which are involved in 

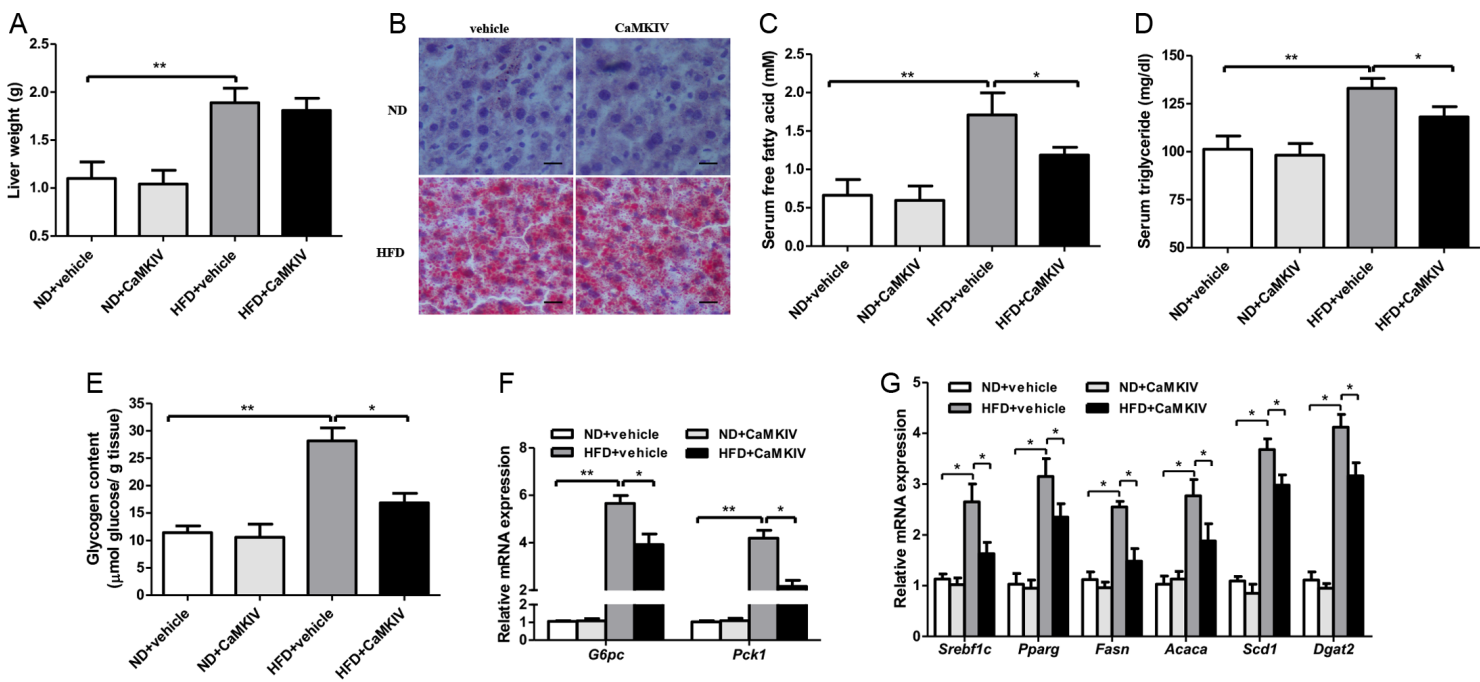

\section{Figure 2}

Effects of CaMKIV on hepatic glucose and lipid metabolism in vivo. All analyses compared age- and sex-matched mice fed a normal diet (ND) or high-fat diet (HFD) for 12 weeks and injected with CaMKIV (1 $\mu \mathrm{g} / \mathrm{g} / \mathrm{day})$ or vehicle in the last 8 weeks. (A) Liver weight. (B) Oil O staining of liver sections (magnification, $\times 100$ ). Scale bar, $20 \mu \mathrm{m}$. (C) Serum free fatty acid. (D) Serum triglyceride. (E) Glycogen content, results are expressed per gram of liver tissues. (F) Relative mRNA expression of gluconeogenesis-associated genes in liver tissues. (G) Relative mRNA expression of lipogenic genes in liver tissues. mRNA levels were examined by quantitative real-time PCR analysis in liver tissues obtained from all the groups. Results are presented as gene expression levels normalized to the average levels of the mean-centered housekeeping gene $\beta$-actin. Data are expressed as means \pm S.D. in each bar graph from 12 to 15 mice per group. $* P<0.05$ or $* \star P<0.01$. A full colour version of this figure is available at https://doi.org/10.1530/JOE-19-0251.

mitochondrial biogenesis both in mRNA and protein levels were significantly decreased in obese mice with vehicle treatment. However, CaMKIV injection significantly induced the mRNA and protein expression of these genes in obese mice (Fig. 3A and B). The alteration of these indicators suggested that mitochondrial biogenesis was improved in obese mice with CaMKIV injection. Consistent with these results, the histomorphometric analysis of liver tissues, adipose tissues and skeletal muscle using electron microscopy showed both mitochondrial area and number were significantly increased in obese mice injected with CaMKIV compared with vehicle injection (Fig. 3C, D and E). These results demonstrated the protective effect of CaMKIV on liver is due to elevated peripheral mitochondrial activity.

\section{Injection of CaMKIV involved in chronic inflammatory response}

To further investigate alleviation of the hepatosteatotic phenotype, we next analyzed key metabolic and inflammatory myokines in serum and their mRNA and protein expression in mice liver tissues. The results indicated serum MCP-1, Fgf21, TNF- $\alpha$ and IL-6 were significantly increased in obese mice with vehicle injection (Fig. 4A, B, C and D). Nevertheless, the increased serum MCP-1 was markedly suppressed in obese mice with CaMKIV treatment (Fig. 4A). Moreover, except serum TNF- $\alpha$ and IL-6, a decrease in trend was also observed in serum Fgf21 in obese mice treated with CaMKIV (Fig. 4B), though the changes did not seem to be remarkable compared with the vehicle $(P=0.057)$, implicating the decreased inflammatory response may contribute to CaMKIV effects. In addition, we found the Mcp-1, a critical gene which involved in mitochondrial biogenesis, Fgf21, Tnf- $\alpha$ and Il-6 mRNA expression were significantly increased in obese mice with vehicle injection, indicating activated inflammatory response which is induced by obesity (Fig. 4E, F, G and H). Remarkably, the results also showed, except Il-6, the expression of Mcp-1, Fgf21 and Tnf- $\alpha$ markedly decreased after CaMKIV treatment in obese mice. Because CaMKIV regulated the mRNA expression of Mcp-1, Fgf21 and Tnf- $\alpha$, we further analyzed the protein expression of these genes. The results showed MCP-1, Fgf21, and TNF- $\alpha$ protein expression were significantly increased in obese mice treated with vehicle (Supplementary Fig. 1C). CaMKIV injection in obese mice significantly inhibited the expression of MCP-1 and Fgf21 (Supplementary Fig. 1C). These results further demonstrated that the effect of CaMKIV on the improvement of obesity-induced hepatic insulin resistance at least partly by reducing the chronic inflammatory response in vivo.

\section{Regulation of CaMKIV in hepatic autophagy and insulin receptor signaling in vivo}

It has been reported that increased hepatic autophagy improves HFD-induced insulin resistance (Codogno \& 

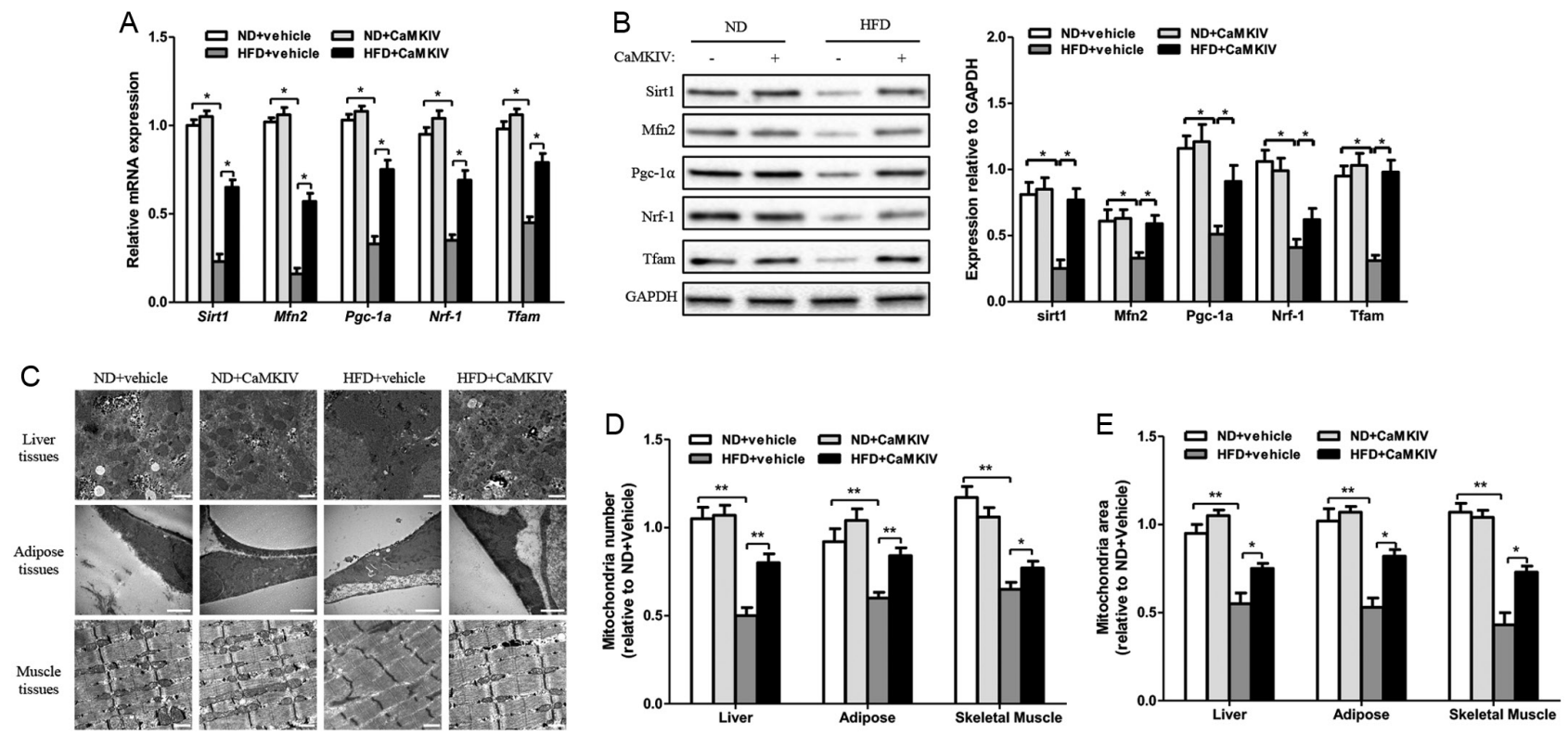

Figure 3

Effect of CaMKIV on mitochondrial function in vivo. All analyses compared age- and sex-matched mice fed a normal diet (ND) or high-fat diet (HFD) for 12 weeks and injected with CaMKIV ( $1 \mu \mathrm{g} / \mathrm{g} /$ day) or vehicle for in last 8 weeks. (A) Relative mRNA expression of mitochondrial function-associated genes in liver tissues. (B) Protein expression of mitochondrial function-associated genes in liver tissues. (C) Representative electron micrographs (40,000×) of mitochondria in liver tissues, adipose tissues and skeletal muscle. Scale bar, $1 \mu \mathrm{m}$. (D and E) Mitochondria number and mitochondria area in liver tissues, adipose tissues, and skeletal muscle, respectively. mRNA levels were examined by quantitative real-time PCR analysis in liver tissues obtained from all the groups. Results are presented as gene expression levels normalized to the average levels of the mean-centered housekeeping gene $\beta$-actin. Data are expressed as means \pm S.D. in each bar graph from 12 to 15 mice per group. $* P<0.05$ or $\star \star P<0.01$.

Meijer 2010, Yang et al. 2010). To further explore the mechanism by which CaMKIV improves diet-induced insulin resistance, we first analyzed liver protein expression of autophagy by Western blotting. As shown in Fig. 5A, there was a remarkable inhibition of autophagy as evidenced by downregulation of LC3II and particularly Atg7. Meanwhile, p62 expression in protein and mRNA levels were elevated in liver tissues of obese mice with
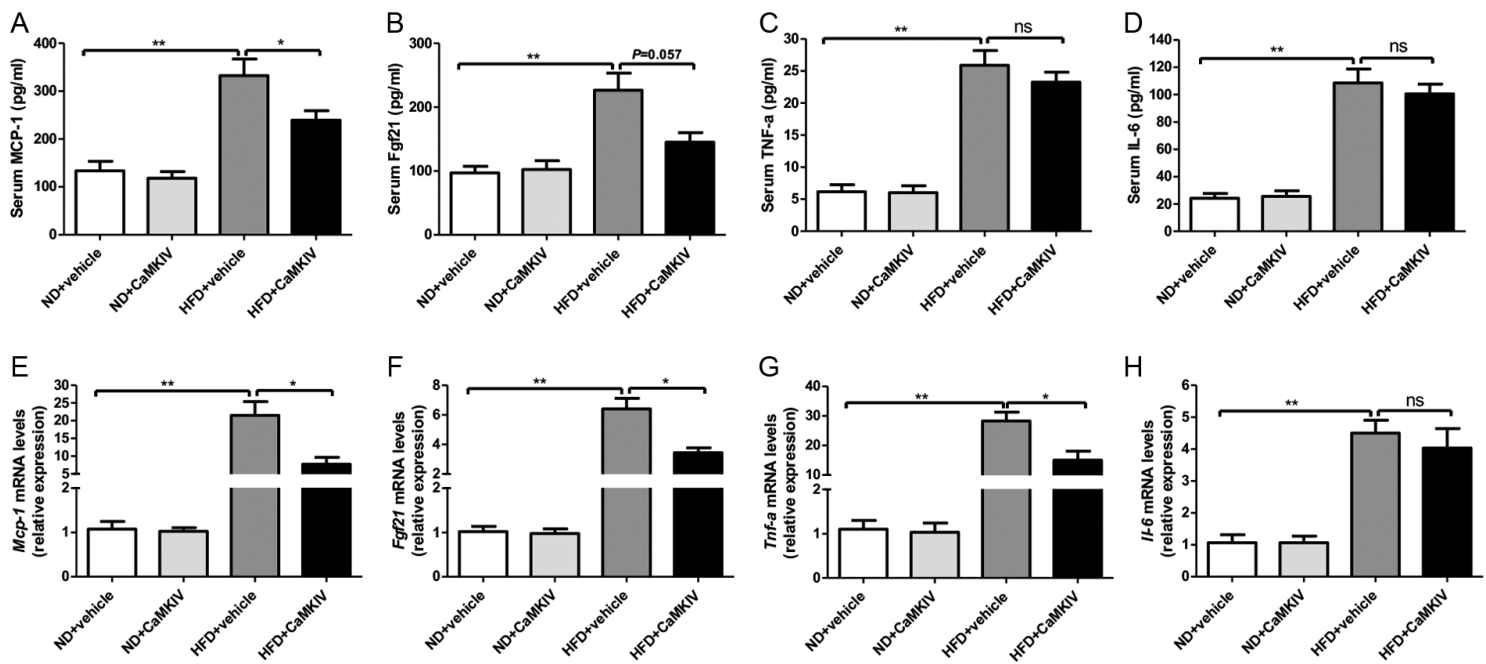

\section{Figure 4}

Effect of CaMKIV on inflammatory response in mice. All analyses compared age- and sex-matched mice fed a normal diet (ND) or high-fat diet (HFD) for 12 weeks and injected with CaMKIV (1 $\mu \mathrm{g} / \mathrm{g} / \mathrm{day})$ or vehicle in the last 8 weeks. (A) Serum MCP-1 level. (B) Serum Fgf21 level. (C) Serum TNF- $\alpha$ level. (D) Serum IL-6 level. (E) Mcp-1 expression. (F) Fgf21 expression. (G) Tnf- $\alpha$ expression. (H) II-6 expression. mRNA levels were examined by quantitative real-time PCR analysis in liver tissues obtained from all the groups. Results are presented as gene expression levels normalized to the average levels of the mean-centered housekeeping gene $\beta$-actin. Data are expressed as means \pm S.D. in each bar graph. $* P<0.05$ or $* * P<0.01$. 
vehicle treatment. However, as a result of CaMKIV injection, obese mice showed an increased Atg7 and LC3II expression (Fig. 5A) and a decreased expression of p62 in protein and mRNA levels compared with vehicle injection (Fig. 5A and B). In addition, long-term injection of CaMKIV in mice showed an increased expression of CaMKIV compared with the vehicle injection (Fig. 5A). We next used lysosomal protease inhibitor chloroquine to evaluate the autophagic flux. Although an increase of LC3II level was readily observable with the treatment of chloroquine, the additional CaMKIV caused a significant difference in the LC3II expression in liver tissues with chloroquine (Fig. 5C). Consistently, the insulin sensitivity was also markedly increased in obese mice with CaMKIV injection compared with vehicle injection as assessed by the phosphorylation of IRS-1 and Akt (Nakatani et al. 2005) (Fig. 5D). These results supported a clear tendency toward the relevance of CaMKIV to hepatic insulin signaling and autophagy.

\section{Effect of CaMKIV on autophagy activity and insulin signaling in hepatocytes}

To elucidate the effects of CaMKIV on autophagy and insulin sensitivity in vitro, we used $100 \mathrm{ng} / \mathrm{mL}$ recombinant mouse CaMKIV at different time points $(0,10,20$ and $40 \mathrm{~h})$ to determine whether overexpression of CaMKIV restores autophagic imbalance and improves insulin signaling on FFA-induced BNL cl.2 hepatocyte models of insulin resistance. As shown in Fig. $6 \mathrm{~A}$ and $\mathrm{C}$, administered with CaMKIV for $20 \mathrm{~h}$ or $40 \mathrm{~h}$ caused a time-dependent increase in protein expression of Atg7 and LC3II as well as a reduction in protein and mRNA expression of p62 in the presence of FFA. It also revealed an increased protein expression of CaMKIV in CaMKIV-treated cells (Fig. 6A). Immunofluorescence for endogenous LC3B revealed decreased puncta in obese mice treated with vehicle but increased puncta in CaMKIV (Fig. 6B), demonstrating the restoration of autophagosome formation. Moreover, it has been reported that abnormal autophagy was implicated in the Akt signaling pathway (Xu et al. 2012); therefore, we postulated that CaMKIV might affect insulin sensitivity in hepatocytes. As expected, improved insulin receptor signaling was observed by the treatment of CaMKIV for $20 \mathrm{~h}$ in hepatocytes, as assessed by phosphorylation of IRS-1 and Akt (Fig. 6D). These results indicated CaMKIV is strongly associated with autophagy activity and insulin receptor signaling at cell level.

To further understand the involvement of CaMKIV in autophagy and insulin signaling in vitro, we used siRNA against CaMKIV to determine whether ablation of CaMKIV could decrease autophagy and impair insulin sensitivity. CaMKIV siRNA (CaMKIVsi) was validated by
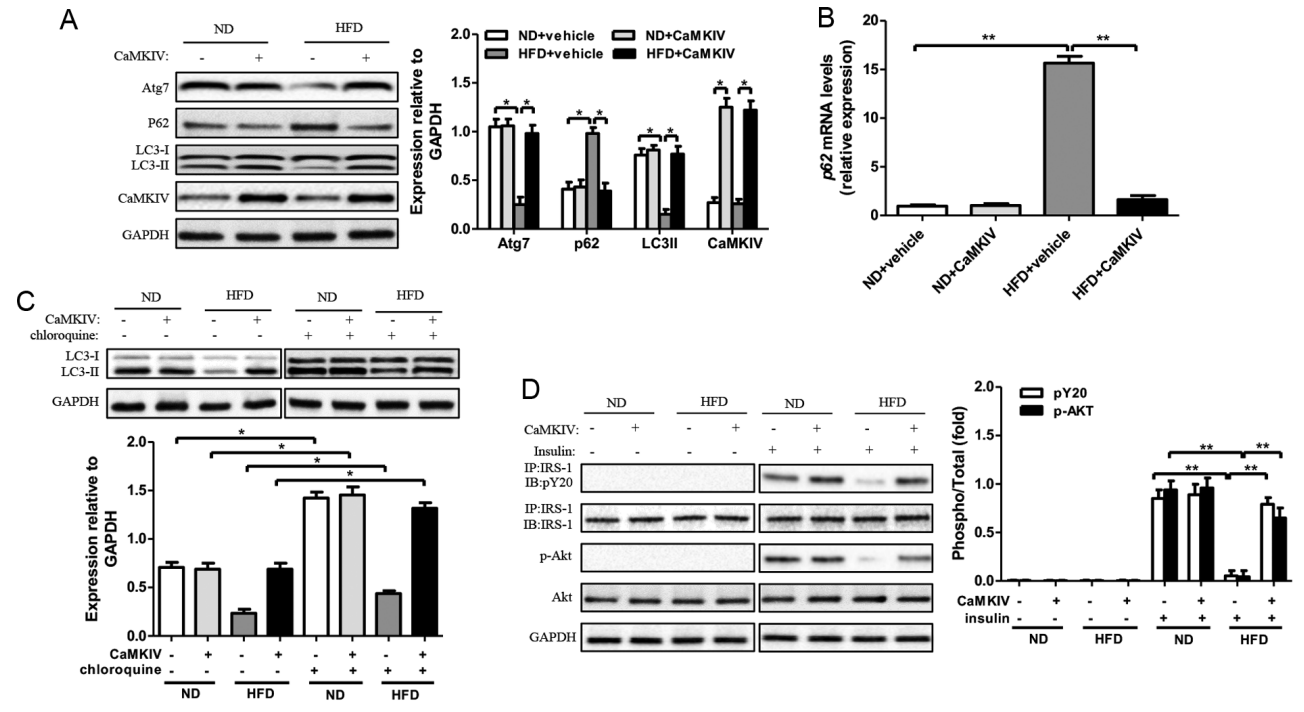

\section{Figure 5}

Effect of CaMKIV on hepatic autophagy and insulin sensitivity in vivo. All analyses compared age- and sex-matched mice fed a normal diet (ND) or high-fat diet (HFD) for 12 weeks and injected with CaMKIV (1 $\mu \mathrm{g} / \mathrm{g} /$ day) or vehicle for in last 8 weeks. For insulin signaling, animals were injected with 2 IU/kg of insulin. (A) Atg7, p62, LC3II, and CaMKIV expression in liver tissues. (B) p62 expression. (C) Determination of autophagic flux in mice receiving CaMKIV in the absence or presence of chloroquine. Liver tissue lysates were analyzed by Western blot using anti-LC3 antibody. Results are given as fold increase normalized to internal control GAPDH. (D) IRS-1 phosphorylation and Akt phosphorylation in liver tissues. Quantification was performed on three different fields per animals. Data are expressed as means \pm S.D. in each bar graph from 12 to 15 mice per group. IB, immunoblotting; IP, immunoprecipitation. $* P<0.05$ or $* * P<0.01$. 


\begin{tabular}{l|l|l|r|r|}
$\begin{array}{l}\text { Journal of } \\
\text { Endocrinology }\end{array}$ & J Liu et al. & $\begin{array}{l}\text { CaMKIV in insulin resistance } \\
\text { and autophagy }\end{array}$ & $\mathbf{2 4 4 : 2}$ & $\mathbf{3 6 1}$ \\
\hline
\end{tabular}

A
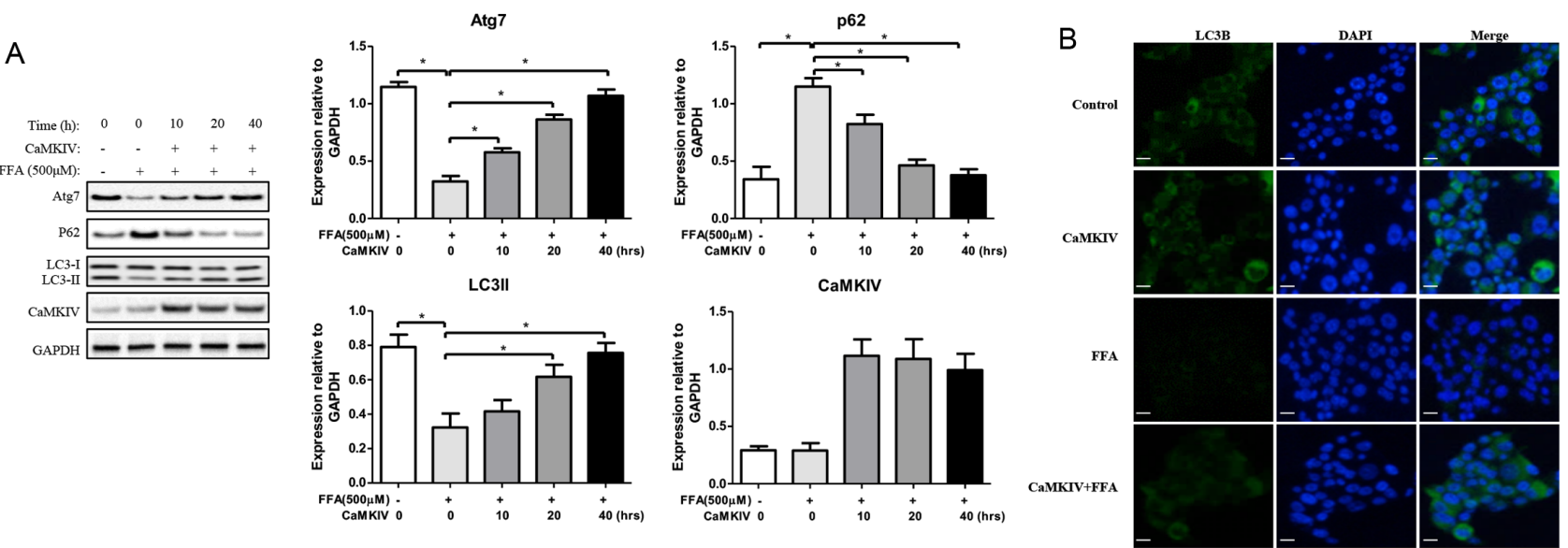

C
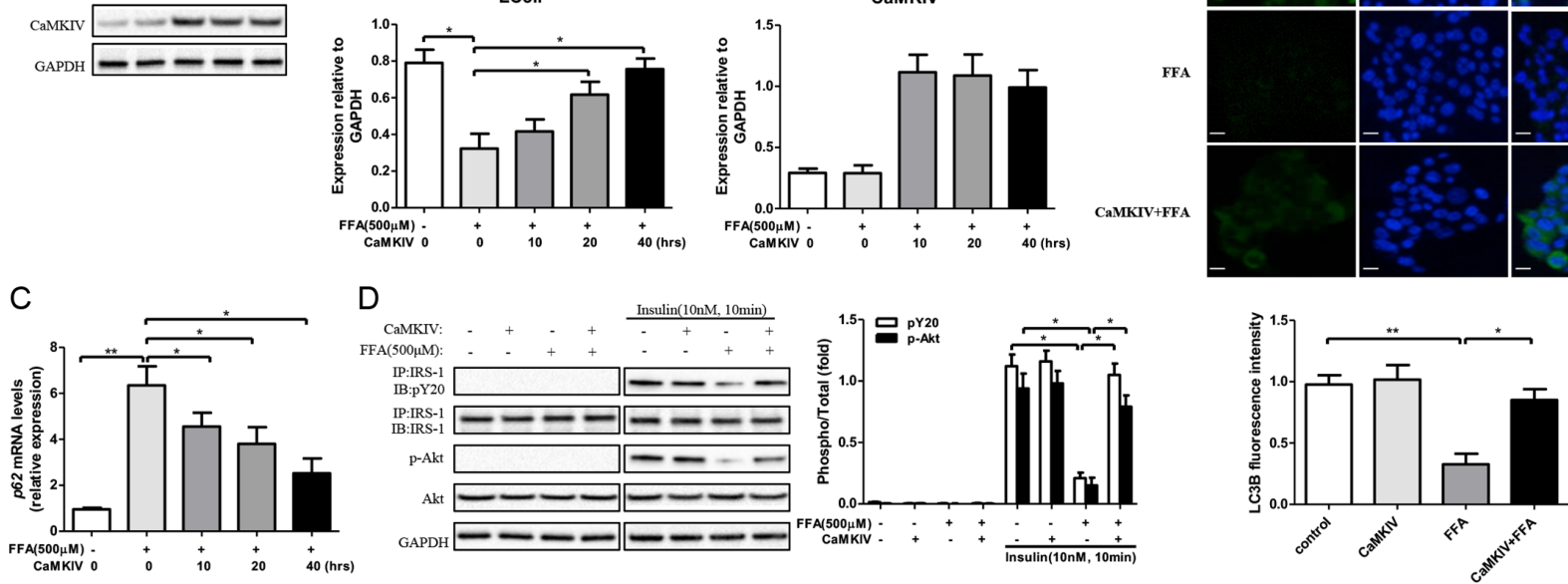

Figure 6

Effect of CaMKIV in autophagy and insulin receptor signaling in FFA-treated hepatocytes. Cells were cultured with or without mouse recombinant CaMKIV $(100 \mathrm{ng} / \mathrm{mL})$. For inducing insulin resistance, cells were cultured with $500 \mu \mathrm{M}$ FFA for $16 \mathrm{~h}$. For insulin signaling, cells were stimulated with $10 \mathrm{nM}$ of insulin for $10 \mathrm{~min}$. Indicators of autophagy and insulin receptor signaling were measured at protein levels. (A) Time course for autophagy indicators and CaMKIV expression in hepatocytes following FFA and/or CaMKIV treatment. (B) Immunofluorescence for endogenous LC3B. Scale bar, 20 mm. Cells were treated with CaMKIV for $20 \mathrm{~h}$ in FFA-induced insulin resistance. (C) p62 expression. (D) Phosphorylation of IRS-1 and Akt in hepatocyte. Data expressed as means \pm S.D. in each bar graph represent the average of three independent experiments. IB, immunoblotting; IP, immunoprecipitation. $\star P<0.05$ or $\star \star P<0.01$.

the measurement of reduced CaMKIV protein expression in CaMKIVsi-transfected BNL cl.2 cells (Fig. 7A). We next detected the indicators of autophagy and insulin receptor signaling after CaMKIVsi transfected hepatocytes for $48 \mathrm{~h}$. The results showed that autophagy was significantly inhibited as evidenced by the decreased expression of Atg7 and LC3II and induced $\mathrm{mRNA}$ and protein expression of p62 in hepatocytes with CaMKIVsi treatment (Fig. 7B and C). Consistent with these results, immunofluorescence of LC3II also suggested decreased number of autophagosome formation in CaMKIV-l- hepatocytes (Fig. 7D). The insulin-simulated phosphorylation of both IRS-1 and Akt was decreased in CaMKIV-knockdown BNL cl.2 hepatocytes (Fig. 7E). These findings demonstrated CaMKIV significantly corrected autophagic imbalance and enhanced insulin sensitivity in hepatocytes.

\section{Effect of CaMKIV on autophagy activity and insulin sensitivity is mediated through phosphorylated CREB in hepatocytes}

It has been reported that activated CaMKIV regulates CREB phosphorylation, a director downstream substrate of CaMKIV, significantly involved in numerous cellular processes (Marie et al. 2005, Sato et al. 2006, Ding et al. 2017). To investigate whether CaMKIV involved in insulin receptor signaling and induced autophagy via phosphorylated CREB, we first observed an induction of CREB phosphorylation and an increased expression of CaMKIV after CaMKIV incubation for $20 \mathrm{~h}$ (Supplementary Fig. 2A and B). In contrast, the decreased of p-CREB and reduced CaMKIV expression were observed after CaMKIVsi treatment for $48 \mathrm{~h}$ (Supplementary Fig. 2C and D). These results indicated the CaMKIV expression involved in CREB phosphorylation through in hepatocytes. We then sought to explore the molecular mechanism of CaMKIV on metabolic regulation in BNL cl. 2 cells. Different strategies (CREB siRNA (CREBsi) or CREB inhibitor 666-15) were used to downregulate CREB in cultured hepatocytes. We first treated cells with FFA to induce insulin resistance. Then the cells were cultured with $100 \mathrm{nM} 666-15$ or 100 nM CREBsi to block the CREB expression and then add $100 \mathrm{ng} / \mathrm{mL}$ CaMKIV into the medium. Consistent with the previous results, an increased Atg7 and LC3II expression and decreased p62 mRNA and protein expression were 
A

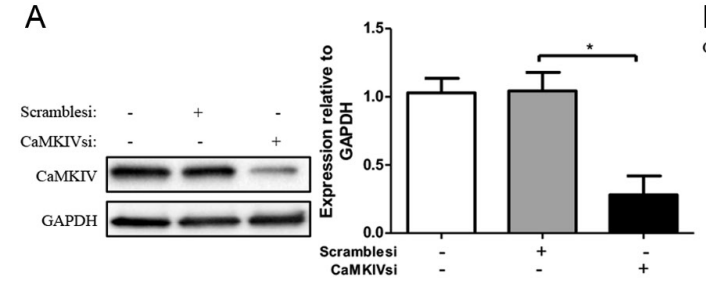

D

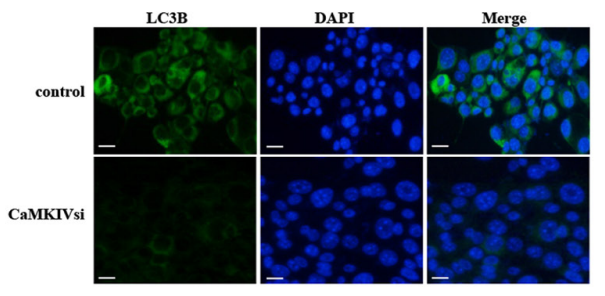

B

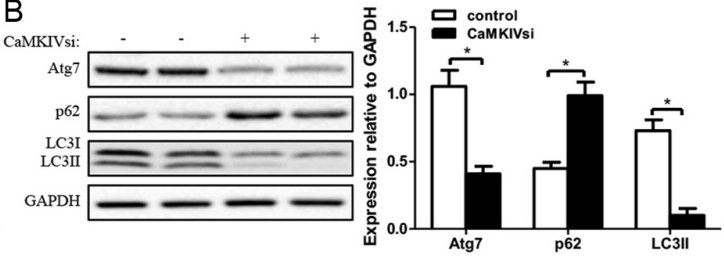

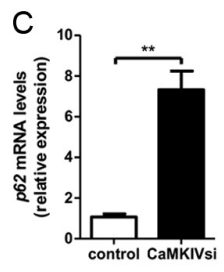

E

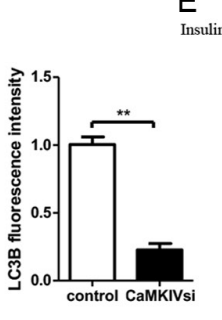

sulin (10nM, 10min):
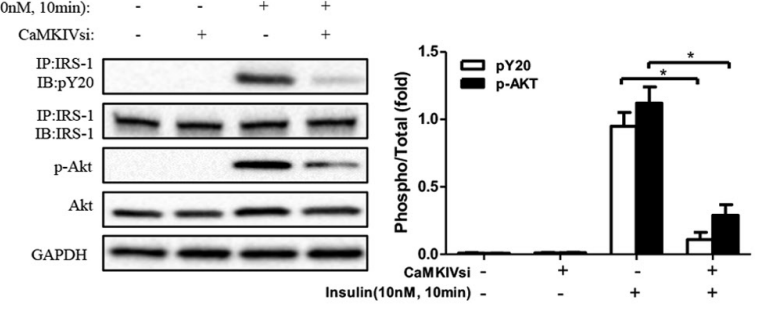

Figure 7

Ablation of CaMKIV decreased autophagy and impaired insulin signaling hepatocytes. Cells were cultured with or without $100 \mathrm{nM}$ CaMKIVsi for $48 \mathrm{~h}$. For insulin signaling, cells were stimulated with $10 \mathrm{nM}$ of insulin for $10 \mathrm{~min}$. Indicators of autophagy and insulin receptor signaling were measured at protein levels. (A) CaMKIVsi was validated by reduction of CaMKIV protein level. (B) Autophagy indicators in hepatocytes. (C) p62 expression. (D) Immunofluorescence for LC3B. Scale bar, $20 \mu \mathrm{m}$. (E) Phosphorylation of IRS-1and Akt in hepatocytes. Data expressed as means \pm S.D. in each bar graph represent the average of three independent experiments. IB, immunoblotting; IP, immunoprecipitation. ${ }^{\star} P<0.05$ or $\star \star P<0.01$.

observed after cells treated with CaMKIV in FFA-induced insulin resistance (Fig. 8A and E). Moreover, CaMKIV also enhanced the IRS-1 and Akt phosphorylation in FFAtreated cells (Fig. 8C). IB analysis showed that insulin induced CREB phosphorylation without altering the total CREB levels and CaMKIV levels, and addition of CaMKIV or CREBsi changed the effect (Fig. 8C). Of note, CaMKIV treatment had no effect on autophagic expression and insulin sensitivity after CREBsi-treated cells. Similar results were observed in 666-15-treated cells, the effect of CaMKIV in induction autophagy (Fig. 8B and F) and improvement of insulin sensitivity were blocked (Fig. 8D). Immunofluorescence for LC3II also demonstrated CaMKIV through p-CREB to regulate autophagy activity in FFA-induced cells (Supplementary Fig. 3). Meantime, our supplemental results further demonstrated that overexpression of CREB enhances the protective effect of CaMKIV on autophagic imbalance and impaired insulin signaling in FFA-induced cell models of insulin resistance (Supplementary Fig. 5). Taken together, these results indicated CREB phosphorylation is required for CaMKIV to reverse autophagic imbalance and improve impaired insulin signaling in FFA-induced insulin resistance models.

\section{Discussion}

Understanding the mechanism of CaMKIV in the progress of insulin sensitivity is of both scientific and clinical significance. CaMKIV is a multifunctional enzyme encoded by the CaMKIV gene in human, its function was best understood in neurons, where it inhibits apoptosis and stimulates growth in a calcium- and CREB-dependent manner (Sée et al. 2001). Earlier study has shown that CaMKIV was also expressed by hepatocytes, but its role in hepatocytes has not been fully defined (Miyano et al. 1992). To our knowledge, this study was the first to investigate the association of exogenous CaMKIV on glucose tolerance, insulin resistance, hepatic autophagy and mitochondrial function in HFD-induced obese mice. To date, all the in vivo or in vitro studies that examined the effect of CaMKIV on insulin secretion, glucose metabolism, and autophagy activity have been conducted in CaMKIV KO or transgenic mice fed with a normal chow (Evankovich et al. 2012, Lee et al. 2014). According to these previous works, our data clearly demonstrated that long-term administration of CaMKIV improved obese-induced insulin resistance. However, much remains to be elucidated regarding the mechanism of CaMKIV action before its putative potential as therapeutic target can be realized.

Recent studies have implicated the activity of CaMKIV not only improved insulin-stimulated muscle glucose uptake in muscle, but also improved liver and adipose insulin action via increases in myokines released from skeletal muscle (Lee et al. 2014). In the present study, mice developed signs of insulin resistance and defective hepatic autophagy upon long-term HFD treatment, and these effects were ameliorated when administrated with recombinant CaMKIV for 8 weeks 

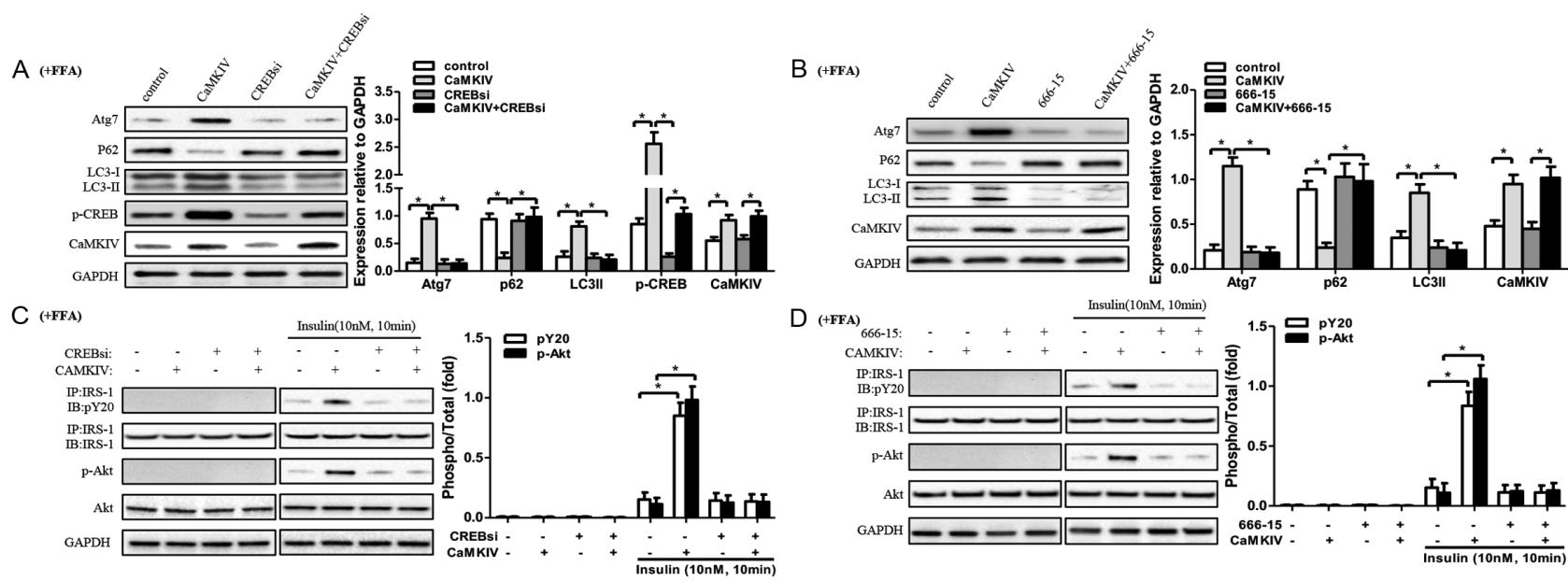

$\mathrm{D}(\mathrm{FFA}){ }_{66}$

Insulin(10nM, 10min)

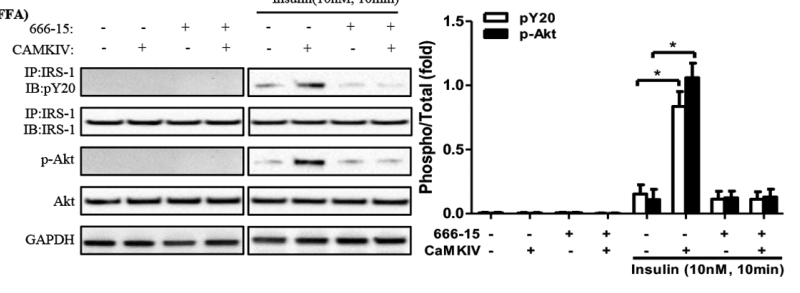

E (FFA)
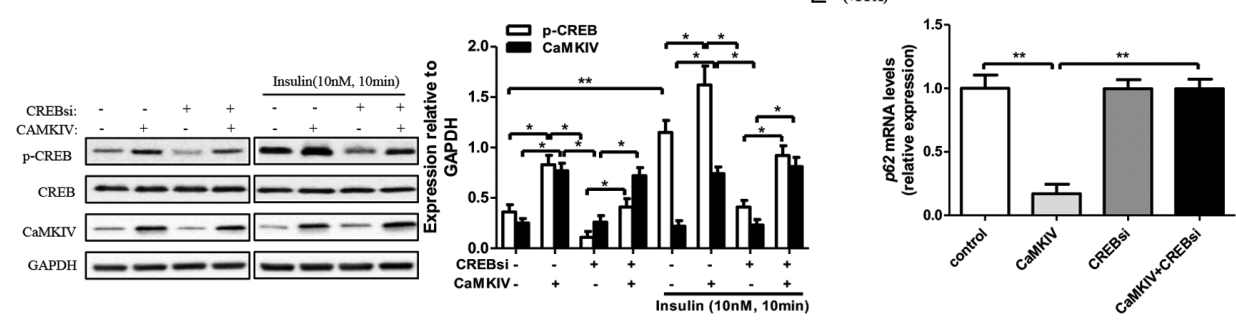

$\mathrm{F}_{(+\mathrm{FFA})}$

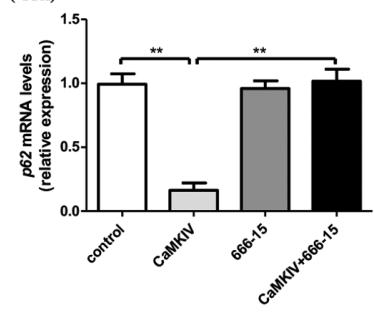

\section{Figure 8}

CaMKIV-dependent CREB phosphorylation in hepatocytes. Cells were cultured with $500 \mu \mathrm{M}$ FFA for $16 \mathrm{~h}$ to induce insulin resistance. For blocking CREB, cells were treated with CREB siRNA (100 nM) for $48 \mathrm{~h}$ or 666-15 (100 nM) for $24 \mathrm{~h}$. Then cells were treated with or without $100 \mathrm{ng} / \mathrm{mL}$ CaMKIV for $20 \mathrm{~h}$. For insulin signaling, cells were stimulated with $10 \mathrm{nM}$ of insulin for $10 \mathrm{~min}$. Indicators of autophagy and insulin receptor signaling were measured at protein levels. (A and B) Expression autophagy indicators, p-CREB and CaMKIV in hepatocytes. (C and D) Phosphorylation of IRS-1 and Akt. (E and F) p62 expression. Data expressed as means \pm S.D. in each bar graph represent the average of three independent experiments. IB, immunoblotting; IP, immunoprecipitation. $* P<0.05$ or $* * P<0.01$.

simultaneously. Consistent with these in vivo findings, CaMKIV also effectively increased autophagy and restored insulin sensitivity through phosphorylation of CREB in hepatocytes. Collectively, these results support the notion that CaMKIV functions as a novel opportunity for treatment of obesity and diabetes.

It has been reported that autophagy plays a significant role in regulating insulin sensitivity in obesity and the development of type 2 diabetes. In obese mice, the early inflammatory response in metabolic diseases, such as diabetes and obesity, was recently shown to result from autophagy disorder (Wang et al. 2013). Most metabolic inflammasome promotes autophagy, induction of which would be expected to serve as a negative- feedback mechanism that limits ER stress and disease progression in adipose tissue (Zhou \& Liu 2010). In contrast, defective autophagy in hepatic showed an increased ER stress and insulin resistance (Yang et al. 2010). Although several mechanisms have been implicated in glucose metabolism and insulin action, the role of CaMKIV as a protective process has been unclear. The exact mechanisms CaMKIV increased autophagy are not fully understand but probably

(C) 2020 Society for Endocrinology Published by Bioscientifica Ltd.
Printed in Great Britain involved in multiple signals. The preliminary study has indicated CaMKIV prevents ubiquitin proteasomal degradation of mTOR by inhibiting GSK3 $\beta$ activity and FBXW7 recruitment, thereby directly augmenting autophagy in both the $\mathrm{M} \varphi$ and the kidney. These CaMKIVdependent processes lending support to the hypothesis that CaMKIV signaling mediated the autophagic response to sepsis (Zhang et al. 2014). More recently, CaMKIV was found to be a protective mechanism in hepatic ischemiareperfusion (I/R) by activating the CREB-mediated autophagy in hepatocytes (Evankovich et al. 2012). Moreover, CaMKIV has been implicated in the progress of some inflammatory diseases. Inhibition of CaMKIV substantially reduced interstitial mononuclear infiltration and subsequent renal fibrosis in a murine model of focal segmental glomerulosclerosis (Ao et al. 2013). However, another study has suggested that CaMKIV prevents HMGB1 release through the regulation of HDAC1 in vivo during liver ischemic-reperfusion injury and in cultured hepatocytes exposed to hypoxia, these results indicated a protective role of CaMKIV in liver during ischemic stress by counterbalancing the inflammatory signals 
(Evankovich et al. 2010). Interestingly, our present study demonstrated that injection of CaMKIV in vivo suppresses the serum MCP-1 level and inhibits inflammatory cytokines including MCP-1, Fgf21, and TNF- $\alpha$ expression on mRNA and/or protein level, although some of these recoveries did not seem to be the most remarkable. These findings might suggest a tissue-specific pattern of CaMKIV in the regulation of chronic inflammatory response. In our study, because CaMKIV is administered systemically, the observed findings cannot be exclusively contributed to CaMKIV itself. The restored hepatic autophagic function could be a reason for the observation. Therefore, the occurrence of decreased inflammatory cytokines suggests that inhibition of chronic inflammatory response in hepatic is most likely not a direct consequence of CaMKIV, but rather could be associated with the restoration of autophagy.

In another aspect, recent evidence indicated that CREB as a transcription regulator participated in autophagy activation (Settembre \& Ballabio 2014). The previous study has identified that downregulation of CREB decreased the expression of autophagy genes and reduced the number of GFP-LC3 puncta in hepatocytes. In addition, overexpression of CREB could reverse the inhibition of autophagy mediated by downregulation of Atg7 (Seok et al. 2014). In our study, we also demonstrated that knockdown of CREB resulted in BNL cl.2 hepatocytes autophagic imbalance (Supplementary Fig. 4), indicating a critical role of CREB in mediating CaMKIV function. These results suggested transcriptional regulation by CREB is probably independent of the acutely acting mTOR, is slower and more persistent. CREB should effectively sustain regulation of autophagy for longer period of times. These several mechanisms showed the critical role of CREB in autophagy. In addition, CREB is one of the most important transcription factors that are phosphorylated and activated by CaMKIV which is involved in different cellular processes such as proliferation, differentiation, apoptosis and survival (Berridge et al. 2000, Finkbeiner 2000, Shankar \& Sakamoto 2004), while no studies have investigated this pathway in hepatic insulin resistance. Therefore, we hypothesized that CaMKIV might improve the impaired hepatic autophagy to increase insulin sensitivity through p-CREB. In this study, we demonstrated p-CREB expression level changed at the presence of insulin, indicating the link between CaMKIV and CREB in liver is present in the insulin-induced insulin receptor and IRS-1 tyrosine phosphorylation. Our results further demonstrated that CaMKIV through p-CREB enhances the autophagy activity and improves insulin signaling and might act as an antidiabetic modality with potential application in the treatment of type 2 diabetes.

Although our results demonstrated CaMKIV-induced autophagy appeared causal to hepatic insulin resistance, a definitive link could be established if restoration autophagy could rescue the impaired insulin sensitivity. Therefore, our study provided the evidence that reconstitution of Atg7 results in enhanced autophagic activity and improved insulin signaling in hepatocytes (Supplementary Fig. 6). Atg7 not only encodes ubiquitinactivating enzyme (E1)-like enzyme but also has been central for autophagosome formation responsible for both Atg12-Atg5 conjugation and LC3 conversion. Previous study showed that the reduced insulin level in obese mice fails to recover Atg7 deficiency, but the suppression of Atg7 directly results in hepatic insulin resistance in lean mice (Kotoulas et al. 2006, Yang et al. 2010). It is nevertheless possible that CaMKIV may contribute to the initiation of autophagic machinery, which would further restore organelle dysfunction and metabolic disorder.

Increasing evidence indicated that decreased mitochondrial number and destroyed mitochondrial function was closely associated with human aging and metabolic diseases, such as type 2 diabetes and obesity (Heinonen et al. 2017, Kauppila et al. 2017, Morio et al. 2019). Thus, improvement of mitochondrial function by exercise training, calories restriction, or resveratrol supplementation has been associated with improved metabolic health in humans. Our in vivo findings provided the evidence that CaMKIV played a significant role in HFD-induced hepatic mitochondrial dysfunction. In our study, obese mice with CaMKIV treatment showed an improvement of GTT and ITT and a restored hepatic mitochondrial function. The exact mechanism by which CaMKIV stimulated mitochondrial mass remains to be determined, but the recent research has reported that CaMKIV could stimulate $P g C-1 \alpha$ gene expression which was involved in mitochondrial biogenesis in skeletal muscle (Lagouge et al. 2006). Earlier studies have reported PGC- $1 \alpha$ as a key regulator of mitochondrial biogenesis was stimulated by CaMKIV expression, and reduced PGC- $1 \alpha$ level seems to be involved in insulin resistance and type 2 diabetes (Wenz 2011). Recent studies also suggested $P g c-1 \alpha$ gene upregulation could balance the production of ATP between mitochondria and nonmitochondria, it could also stimulate the other mitochondria biogenesisrelated genes (such as Nrf1 and Nrf2 expression), and 
coactivate several mitochondrial regulatory factors including Mef2 and Ppars (Czubryt et al. 2003, Wenz 2011, 2013). In addition, NRF2 has been implicated in the control of Tfam expression which is well known to regulate mtDNA transcription and replication. MFN2 was identified as an important factor to regulate mitochondrial fusion and protect mitochondrial function (Chen et al. 2003). Remarkably, our findings showed that CaMKIV upregulated the expression of $P g c-1 \alpha$, Sirt1, Mfn2, Nrf-1 and Tfam mRNA expression in liver tissues of obese mice. These results indicated that CaMKIV effectively restored mitochondrial function through upregulation of mitochondrial biogenesisassociated genes. Therefore, the effect of CaMKIV on improvement of insulin sensitivity might have contributed to the restoration of hepatic mitochondrial function.

In conclusion, our study revealed that administration of CaMKIV in obese mice improved hepatic insulin sensitivity and suggested a causal link between CaMKIV, impaired hepatic insulin signaling, and defective hepatic autophagy. Our findings may implicate modulated CaMKIV secretion/action as a promising therapeutic approach in metabolic disorders.

\section{Supplementary materials}

This is linked to the online version of the paper at https://doi.org/10.1530/ JOE-19-0251.

\section{Declaration of interest}

The authors declare that there is no conflict of interest that could be perceived as prejudicing the impartiality of the research reported

\section{Funding}

This study was partly supported by funds from the National Natural Science Foundation of China (Program No. 81600619), Natural Science Foundation of Shaanxi Province (No. 708037169021) and Personal Training Special Fund of the Second Affiliated Hospital of Xi'an Jiaotong University (No. RC(XM)2016010)

\section{Author contribution statement}

$L J L, L Y, L S Y$ and $Z X$ processed the samples, analyzed and prepared the data, and were involved in drafting the article. $L J L, Z X Y, Z L, H J T$ and $\mathrm{M} \mathrm{H}$ contributed to data interpretation and revised the article. $\mathrm{L} J \mathrm{~L}, \mathrm{H} Q$ and $G$ Y designed the experiments, interpreted the data, and was primary responsible for writing the manuscript. All authors approved the final version of the manuscript.

(C) 2020 Society for Endocrinology Published by Bioscientifica Ltd. Printed in Great Britain

\section{Acknowledgements}

The authors appreciate the technical support and materials from the electron microscope center and laboratory animal center of Xi'an Jiaotong University.

\section{References}

Ao Q, Cheng Q, Ma Q, Wang X \& Liu S 2013 Inhibition of calcium2+/ calmodulin-dependent protein kinase type IV ameliorates experimental nephrotic syndrome. Internal Medicine 52 1035-1041. (https://doi.org/10.2169/internalmedicine.52.9574)

Berridge MJ, Lipp P \& Bootman MD 2000 The versatility and universality of calcium signalling. Nature Reviews: Molecular Cell Biology 1 11-21. (https://doi.org/10.1038/35036035)

Bojsen-Møller KN, Lundsgaard AM, Madsbad S, Kiens B \& Holst JJ 2018 Hepatic insulin clearance in regulation of systemic insulin concentrations - role of carbohydrate and energy availability. Diabetes 67 2129-2136. (https://doi.org/10.2337/db18-0539)

Calomeni GD, Ataíde EB, Machado RR, Escanhoela CA, Costa LB \& Boin IF 2013 Hepatic inflammatory pseudotumor: a case series. International Journal of Surgery Case Reports 4 308-311. (https://doi. org/10.1016/j.ijscr.2013.01.002)

Chen H, Detmer SA, Ewald AJ, Griffin EE, Fraser SE \& Chan DC 2003 Mitofusins Mfn1 and Mfn2 coordinately regulate mitochondrial fusion and are essential for embryonic development. Journal of Cell Biology 160 189-200. (https://doi.org/10.1083/jcb.200211046)

Cho HI, Choi JW \& Lee SM 2014 Impairment of autophagosomelysosome fusion contributes to chronic ethanol-induced liver injury. Alcohol 48 717-725. (https://doi.org/10.1016/j.alcohol.2014.08.006)

Codogno P \& Meijer AJ 2010 Autophagy: a potential link between obesity and insulin resistance. Cell Metabolism 11 449-451. (https://doi. org/10.1016/j.cmet.2010.05.006)

Craft S \& Rhoads K 2016 Insulin resistance syndrome and Alzheimer's disease. Neurobiology of Aging 26 (Suppl 1) 65-69. (https://doi.org/10. 1016/j.neurobiolaging.2005.08.021)

Czubryt MP, McAnally J, Fishman GI \& Olson EN 2003 Regulation of peroxisome proliferator-activated receptor $\gamma$ coactivator $1 \alpha$ (PGC$1 \alpha$ ) and mitochondrial function by MEF2 and HDAC5. PNAS 100 1711-1716. (https://doi.org/10.1073/pnas.0337639100)

Ding S, Zhuge W, Yang J, Wen F, Xu Z, Wang X \& Zhuge Q 2017 Insulin resistance disrupts the interaction between AKT and the NMDA receptor and the inactivation of the CaMKIV/CREB pathway in minimal hepatic encephalopathy. Toxicological Sciences 159 290-306 (https://doi.org/10.1093/toxsci/kfx093)

Evankovich J, Cho S, Cardinal J, Dhupar R, Klune J, Rosengart M, Geller D \& Tsung AJJoSR 2010 Calcium/calmodulin protein kinase IV prevents high mobility group box protein 1 release during hepatic ischemia/reperfusion injury through regulation of histone deacetylase 1. Journal of Surgical Research 158 350. (https://doi.org/10.1016/j.jss .2009.11.490)

Evankovich J, Zhang R, Cardinal JS, Zhang L, Chen J, Huang H, Beer-Stolz D, Billiar TR, Rosengart MR \& Tsung A 2012 Calcium/ calmodulin-dependent protein kinase IV limits organ damage in hepatic ischemia-reperfusion injury through induction of autophagy. American Journal of Physiology: Gastrointestinal and Liver Physiology $\mathbf{3 0 3}$ G189-G198. (https://doi.org/10.1152/ajpgi.00051.2012)

Finkbeiner S 2000 CREB couples neurotrophin signals to survival messages. Neuron 25 11-14. (https://doi.org/10.1016/s08966273(00)80866-1)

Fukushima H, Maeda R, Suzuki R, Suzuki A, Nomoto M, Toyoda H, Wu LJ, Xu H, Zhao MG, Ueda K, et al. 2008 Upregulation of calcium/ calmodulin-dependent protein kinase IV improves memory formation and rescues memory loss with aging. Journal of Neuroscience $\mathbf{2 8}$ 9910-9919. (https://doi.org/10.1523/JNEUROSCI.2625-08.2008) 
Hanissian SH, Frangakis M, Bland MM, Jawahar S \& Chatila TA 1993 Expression of a $\mathrm{Ca} 2+/$ calmodulin-dependent protein kinase, $\mathrm{CaM}$ kinase-Gr, in human T lymphocytes. Regulation of kinase activity by T cell receptor signaling. Journal of Biological Chemistry 268 20055-20063.

Heinonen S, Muniandy M, Buzkova J, Mardinoglu A, Rodríguez A, Frühbeck G, Hakkarainen A, Lundbom J, Lundbom N, Kaprio J, et al. 2017 Mitochondria-related transcriptional signature is downregulated in adipocytes in obesity: a study of young healthy MZ twins. Diabetologia 60 169-181. (https://doi.org/10.1007/ s00125-016-4121-2)

Hook SS \& Means AR 2001 Ca2+/CaM-dependent kinases: from activation to function. Annual Review of Pharmacology and Toxicology 41 471-505. (https://doi.org/10.1146/annurev.pharmtox.41.1.471)

Kang H, Sun LD, Atkins CM, Soderling TR, Wilson MA \& Tonegawa S 2001 An important role of neural activity-dependent CaMKIV signaling in the consolidation of long-term memory. Cell $\mathbf{1 0 6}$ 771-783. (https://doi.org/10.1016/s0092-8674(01)00497-4)

Kauppila TES, Kauppila JHK \& Larsson NG 2017 Mammalian mitochondria and aging: an update. Cell Metabolism 25 57-71. (https://doi.org/10.1016/j.cmet.2016.09.017)

Koliaki C \& Roden M 2013 Hepatic energy metabolism in human diabetes mellitus, obesity and non-alcoholic fatty liver disease. Molecular and Cellular Endocrinology 379 35-42. (https://doi. org/10.1016/j.mce.2013.06.002)

Koliaki C, Szendroedi J, Kaul K, Jelenik T, Nowotny P, Jankowiak F, Herder C, Carstensen M, Krausch M, Knoefel WT, et al. 2015 Adaptation of hepatic mitochondrial function in humans with non-alcoholic fatty liver is lost in steatohepatitis. Cell Metabolism 21 739-746. (https://doi.org/10.1016/j.cmet.2015.04.004)

Kotoulas OB, Kalamidas SA \& Kondomerkos DJ 2006 Glycogen autophagy in glucose homeostasis. Pathology, Research and Practice 202 631-638. (https://doi.org/10.1016/j.prp.2006.04.001)

Lagouge M, Argmann C, Gerhart-Hines Z, Meziane H, Lerin C, Daussin F, Messadeq N, Milne J, Lambert P, Elliott P, et al. 2006 Resveratrol improves mitochondrial function and protects against metabolic disease by activating SIRT1 and PGC-1 $\alpha$. Cell 127 1109-1122. (https:// doi.org/10.1016/j.cell.2006.11.013)

Lee H-Y, Gattu AK, Camporez J-PG, Kanda S, Guigni B, Kahn M, Zhang D, Galbo T, Birkenfeld AL \& Jornayvaz FR 2014 Muscle-specific activation of $\mathrm{Ca} 2+/$ calmodulin-dependent protein kinase IV increases whole-body insulin action in mice. Diabetologia 57 1232-1241. (http s://doi.org/10.1007/s00125-014-3212-1)

Li H, Zhou B, Xu L, Liu J, Zang W, Wu S \& Sun H $2014 a$ The reciprocal interaction between autophagic dysfunction and ER stress in adipose insulin resistance. Cell Cycle 13 565-579. (https://doi.org/10.4161/ cc.27406)

Li Y, Wong K, Giles A, Jiang J, Lee JW, Adams AC, Kharitonenkov A, Yang Q, Gao B, Guarente L, et al. 2014b Hepatic SIRT1 attenuates hepatic steatosis and controls energy balance in mice by inducing fibroblast growth factor 21. Gastroenterology 146 539.e7-549.e7. (https://doi.org/10.1053/j.gastro.2013.10.059)

Liu J, Li H, Zhou B, Xu L, Kang X, Yang W, Wu S \& Sun H 2015 PGRN induces impaired insulin sensitivity and defective autophagy in hepatic insulin resistance. Molecular Endocrinology 29 528-541. (https://doi.org/10.1210/me.2014-1266)

Marie H, Morishita W, Yu X, Calakos N \& Malenka RC 2005 Generation of silent synapses by acute in vivo expression of CaMKIV and CREB. Neuron 45 741-752. (https://doi.org/10.1016/j.neuron.2005.01.039)

Miyano O, Kameshita I \& Fujisawa H 1992 Purification and characterization of a brain-specific multifunctional calmodulindependent protein kinase from rat cerebellum. Journal of Biological Chemistry 267 1198-1203.

Montgomery MK \& Turner N 2015 Mitochondrial dysfunction and insulin resistance: an update. Endocrine Connections 4 R1-R15. (https://doi.org/10.1530/EC-14-0092)
Morio B, Pénicaud L \& Rigoulet M 2019 Mitochondria in obesity and Type 2 diabetes: concluding review and research perspectives. In Mitochondria in Obesity and Type 2 Diabetes, pp 421-431. Amsterdam, Netherlands: Elsevier. (https://doi.org/10.1016/B978-0-12-811752-1.0 0018-3)

Murao K, Li J, Imachi H, Muraoka T, Masugata H, Zhang GX, Kobayashi R, Ishida T \& Tokumitsu H 2009 Exendin-4 regulates glucokinase expression by CaMKK/CaMKIV pathway in pancreatic $\beta$-cell line. Diabetes, Obesity and Metabolism 11 939-946. (https://doi. org/10.1111/j.1463-1326.2009.01067.x)

Nakatani Y, Kaneto H, Kawamori D, Yoshiuchi K, Hatazaki M, Matsuoka T-A, Ozawa K, Ogawa S, Hori M \& Yamasaki YJJoBC 2005 Involvement of endoplasmic reticulum stress in insulin resistance and diabetes. Journal of Biological Chemistry 280 847-851. (https://doi.or g/10.1074/jbc.M411860200)

Odegaard JI \& Chawla A 2013 Pleiotropic actions of insulin resistance and inflammation in metabolic homeostasis. Science 339 172-177. (https://doi.org/10.1126/science.1230721)

Persaud SJ, Liu B, Sampaio HB, Jones PM \& Muller DS 2011 Calcium/ calmodulin-dependent kinase IV controls glucose-induced Irs2 expression in mouse beta cells via activation of cAMP response element-binding protein. Diabetologia 54 1109-1120. (https://doi. org/10.1007/s00125-011-2050-7)

Petersen KF, Dufour S, Befroy D, Garcia R \& Shulman GI 2004 Impaired mitochondrial activity in the insulin-resistant offspring of patients with type 2 diabetes. New England Journal of Medicine 350 664-671. (https://doi.org/10.1056/NEJMoa031314)

Racioppi L \& Means AR 2008 Calcium/calmodulin-dependent kinase IV in immune and inflammatory responses: novel routes for an ancient traveller. Trends in Immunology 29 600-607. (https://doi.org/10.1016/j. it.2008.08.005)

Samuel VT \& Shulman GI 2012 Mechanisms for insulin resistance: common threads and missing links. Cell 148 852-871. (https://doi. org/10.1016/j.cell.2012.02.017)

Sato K, Suematsu A, Nakashima T, Takemoto-Kimura S, Aoki K, Morishita Y, Asahara H, Ohya K, Yamaguchi A, Takai T, et al. 2006 Regulation of osteoclast differentiation and function by the CaMK-CREB pathway. Nature Medicine 12 1410-1416. (https://doi. org/10.1038/nm1515)

Sée V, Boutillier AL, BITO H \& Loeffler JP 2001 Calcium/calmodulindependent protein kinase type IV (CaMKIV) inhibits apoptosis induced by potassium deprivation in cerebellar granule neurons. FASEB Journal 15 134-144. (https://doi.org/10.1096/fj.00-0106com)

Seok S, Fu T, Choi SE, Li Y, Zhu R, Kumar S, Sun X, Yoon G, Kang Y, Zhong W, et al. 2014 Transcriptional regulation of autophagy by an FXR-CREB axis. Nature 516 108-111. (https://doi.org/10.1038/ nature13949)

Settembre C \& Ballabio A 2014 Cell metabolism: autophagy transcribed. Nature 516 40-41. (https://doi.org/10.1038/nature13939)

Shankar DB \& Sakamoto KM 2004 The role of cyclic-AMP binding protein (CREB) in leukemia cell proliferation and acute leukemias. Leukemia and Lymphoma 45 265-270. (https://doi.org/10.1080/104281903100 0151095)

Tangvarasittichai S 2015 Oxidative stress, insulin resistance, dyslipidemia and type 2 diabetes mellitus. World Journal of Diabetes 6 456-480. (https://doi.org/10.4239/wjd.v6.i3.456)

Wang Y, Li YB, Yin JJ, Wang Y, Zhu LB, Xie GY \& Pan SH 2013 Autophagy regulates inflammation following oxidative injury in diabetes. Autophagy 9 272-277. (https://doi.org/10.4161/ auto.23628)

Wenz T 2011 Mitochondria and PGC-1 $\alpha$ in aging and age-associated diseases. Journal of Aging Research 2011 810619. (https://doi. org/10.4061/2011/810619)

Wenz T 2013 Regulation of mitochondrial biogenesis and PGC-1 $\alpha$ under cellular stress. Mitochondrion 13 134-142. (https://doi.org/10.1016/j. mito.2013.01.006 https://joe.bioscientifica.com

https://doi.org/10.1530/JOE-19-0251
(C) 2020 Society for Endocrinology Published by Bioscientifica Ltd. Printed in Great Britain 
Wu JY, Ribar TJ, Cummings DE, Burton KA, McKnight GS \& Means AR 2000 Spermiogenesis and exchange of basic nuclear proteins are impaired in male germ cells lacking Camk4. Nature Genetics $\mathbf{2 5}$ 448-452. (https://doi.org/10.1038/78153)

Xu X \& Ren JJC 2012 Unmasking the janus faces of autophagy in obesity-associated insulin resistance and cardiac dysfunction. Clinical and Experimental Pharmacology and Physiology 39 200-208. (https://d oi.org/10.1111/j.1440-1681.2011.05638.x)

Yang L, Li P, Fu S, Calay ES \& Hotamisligil GS 2010 Defective hepatic autophagy in obesity promotes ER stress and causes insulin resistance. Cell Metabolism 11 467-478. (https://doi.org/10.1016/j. cmet.2010.04.005)

Yu X, Murao K, Sayo Y, Imachi H, Cao WM, Ohtsuka S, Niimi M, Tokumitsu H, Inuzuka H, Wong NC, et al. 2004 The role of calcium/ calmodulin-dependent protein kinase cascade in glucose upregulation of insulin gene expression. Diabetes 53 1475-1481. (https://doi. org/10.2337/diabetes.53.6.1475)
Zhang X, Howell GM, Guo L, Collage RD, Loughran PA, Zuckerbraun BS \& Rosengart MR 2014 CaMKIV-dependent preservation of mTOR expression is required for autophagy during lipopolysaccharideinduced inflammation and acute kidney injury. Journal of Immunology 193 2405-2415. (https://doi.org/10.4049/jimmunol.1302798)

Zhou L \& Liu F 2010 Autophagy: roles in obesity-induced ER stress and adiponectin downregulation in adipocytes. Autophagy 6 1196-1197. (https://doi.org/10.4161/auto.6.8.13478)

Zhou B, Li H, Xu L, Zang W, Wu S \& Sun H 2013 Osteocalcin reverses endoplasmic reticulum stress and improves impaired insulin sensitivity secondary to diet-induced obesity through nuclear factorkappaB signaling pathway. Endocrinology 154 1055-1068. (https://doi. org/10.1210/en.2012-2144)

Zois CE, Giatromanolaki A, Sivridis E, Papaiakovou M, Kainulainen H \& Koukourakis MI 2011 'Autophagic flux' in normal mouse tissues: focus on endogenous LC3A processing. Autophagy 7 1371-1378. (https://doi.org/10.4161/auto.7.11.16664)

Received in final form 13 November 2019

Accepted 22 November 2019

Accepted Manuscript published online 22 November 2019
(C) 2020 Society for Endocrinology Published by Bioscientifica Ltd. 